\section{A substância natural do conhecimento}

\author{
Por Neusa Pressler \\ Universidade da Amazônia \\ (neusapressler@unama.br)
}

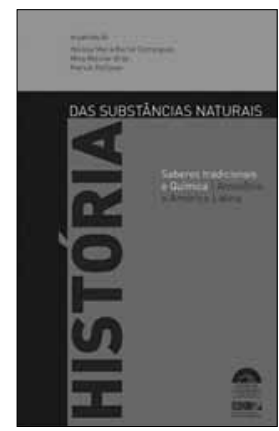

DOMINGUES, Heloisa Maria Bertol; KLEICHEDRAY, Mina; PETITJEAN,

Patrick (Orgs.). História das substâncias naturais Saberes tradicionais e química. Amazônia e América Latina. Rio de Janeiro: MAST/MCTI; Paris:

IRD, 2012. 288 p. ISBN 978-85-60069-39-2

Este livro traz um conjunto de estudos de autores/ pesquisadores que abordam a história dos saberes botânicos, médicos, químicos e das populações locais. O livro trata, especificamente, da transformação da química, na Amazônia e no Brasil, em comparação com o México e a Argentina.

A obra é o resultado de uma intensa e longa pesquisa, e constitui uma cuidadosa coletânea de um projeto científico no âmbito da história das teorias e práticas das ciências da natureza e da antropologia. Os trabalhos que compõem o livro foram originalmente apresentados em três seminários internacionais sobre o tema "História e Sociologia da Química na América Latina", organizados no Brasil, entre os anos de 2008 e 2011. O primeiro ocorreu no Rio de Janeiro (RJ), em outubro de 2008, e abordou "A produção e a utilização dos saberes na Amazônia"; o segundo, "Encontros e circulação dos conhecimentos científicos e dos saberes tradicionais sobre os produtos naturais", ocorreu em Belém, em novembro de 2009; e o último, "Autonomia e legitimidade dos saberes tradicionais na Amazônia", em Manaus, em abril de 2011. Os seminários fizeram parte do projeto de cooperação internacional "História e Sociologia da Química: uso e produção dos saberes" (Conselho Nacional de Desenvolvimento Científico e Tecnológico CNPq), coordenado pelos organizadores do livro e por Diana Antonaz, da Universidade Federal do Pará (UFPA).

Baseado nos seminários e na experiência dos autores, o livro mostra, historicamente, o papel e a importância dos saberes botânicos, médicos e químicos das substâncias naturais utilizadas no final do século XIX e suas transformações até a contemporaneidade. Assim, com uma abordagem atual e abrangente, o trabalho busca subsídios na história para entender as relações desses saberes nas implicações políticas e econômicas da sociedade de consumo, e também das populações locais produtoras dos saberes tradicionais, que não se veem isoladas.

O livro reúne oito artigos de treze autores, a maioria historiadores das ciências de várias universidades e instituições brasileiras e estrangeiras. De leitura cativante pela clareza, pela objetividade, pela experiência e pelo conhecimento científico, o livro oportuniza a discussão dos temas da biodiversidade, do conhecimento tradicional e do etnoconhecimento, questões em pauta na agenda global. A capacidade dos autores de tratar a ciência sob o ponto de vista da história transforma a obra em algo que está além de um relato ou guia para descobrir a história das substâncias naturais e dos saberes das populações tradicionais na Amazônia. Trata-se de uma obra rica em fontes de observação e informação sobre as diferentes formas de entender o que se passa na Amazônia em termos de história, sociologia, etnoconhecimento e saberes naturais.

Conforme os organizadores, na introdução do livro, a expansão do mercado colonial marca o desenvolvimento da química, notadamente, como auxiliar da botânica. Após 1945, ela passou a se relacionar às políticas de desenvolvimento. Desde o início da década de 1990, em virtude da discussão da agenda global de preservação das florestas tropicais, na qual a Amazônia é protagonista, a região vive forte e crescente influência do ambientalismo. Desse modo, cresce o debate em torno

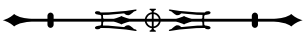


da biodiversidade e da utilização de forma sustentável dos produtos da floresta. Com isso, as populações e os conhecimentos tradicionais ganham visibilidade no contexto da agenda global. Nessa fase, várias indústrias recebem incentivos fiscais, instalam-se e desenvolvem produtos na região. Graças a essa visibilidade, os conhecimentos tradicionais são valorizados e tornamse temas de políticas públicas. Assim, segundo a obra, os produtos da biodiversidade despertam crescente interesse nas indústrias e nos consumidores.

Os capítulos analisam períodos distintos, mas convergem, tendo como pontos de partida ora a botânica, ora a química. Nesse sentido, seguem o mesmo caminho transdisciplinar em torno de um mesmo objeto, os conhecimentos tradicionais e as ciências, especificamente a química, que contribuiu para a exploração dos recursos naturais ao longo do século $X X$. A obra é mais do que uma introdução à história dos saberes botânicos, médicos e químicos acerca das substâncias naturais, pois trata das principais questões ligadas à Amazônia, sob a ótica das Ciências Humanas. Desse modo, pela abrangência do livro, cabe fazer uma síntese de cada capítulo e apresentar de forma resumida o que o leitor encontrará.

O capítulo "A construção de um espaço de investigação química sobre as substâncias naturais presentes na flora regional na Argentina (1854-1920)", de Gabriel Augusto Matharan, historiador das ciências e professor do Centro de Ciência, Tecnología y Sociedad (CCTS), na Argentina, abre o livro analisando os processos institucionais que delinearam o desenvolvimento das pesquisas sobre a química das plantas argentinas. Trata-se de uma análise das primeiras instituições científicas que trabalharam com as plantas nativas. Nesse contexto, a primeira abordagem é sobre a matéria química farmacêutica e sobre a história da química na Argentina, que, segundo o autor, confunde-se com a história das faculdades de farmácia. Nesse país, a química conquistou sua autonomia no final do século XIX e, mais tarde, ampliou seu campo de estudo, abrangendo as plantas alimentícias. O capítulo apresenta um panorama dos conhecimentos tradicionais, das ciências e da história da química na Argentina entre o fim do século XIX e o início do XX.

Patrick Petitjean, historiador das ciências, evidencia, em "Auguste Chevalier, Paul Le Cointe e a Amazônia: as plantas úteis entre a botânica colonial e a etnobotânica", o paradoxo do surgimento da etnobotânica no âmbito das ciências coloniais na França. A descrição de 'plantas úteis' estabelece o elo para a valorização colonial das relações com a natureza, além do interesse da colonização política. O capítulo enfoca a trajetória do químico francês Paulo Le Cointe, que se instalou na Amazônia (1891-1956) e manteve contato regular com os geógrafos coloniais franceses e com as redes de Auguste Chevalier. A descrição dessa trajetória coincide, segundo o autor, com meio século de transformação das práticas científicas em relação às plantas amazônicas, que ampliam o conhecimento sobre botânica e química e as aplicações comerciais. $\bigcirc$ texto ressalta que Le Cointe dedicou os vinte últimos anos de sua vida à assessoria de autoridades no Pará, com o objetivo de potencializar o desenvolvimento comercial e a utilização das plantas nativas. É um estudo que mistura biografia e contexto histórico para evidenciar a pesquisa sobre plantas nativas no âmbito da botânica colonial e da etnobotânica.

A historiadora da ciência Heloisa Maria Bertol Domingues, em "A botânica de Adolpho Ducke: entre a química e os conhecimentos tradicionais", nos oferece um interessante texto que caracteriza os estudos de Adolpho Ducke, no período de 1920 a 1950, e o seu papel de passagem entre os conhecimentos tradicionais e os de laboratório. A partir do modo de pensar de Ducke, na visão da historiadora, a química dá validade científica à utilização comercial de plantas, especialmente as nativas. A postura científica de Ducke o direciona a participar de instituições como a Brazilian American Rubber Party (1940) e a Hileia (1950). Ele buscou, nos métodos nativos, a base dos anestésicos.

Mina Kleiche-Dray, historiadora da ciência, dá continuidade às análises sobre a história das substâncias, propostas no livro, com o capítulo "Construção de objeto

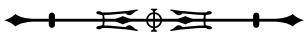


de pesquisa e estruturação disciplinar: plantas medicinais, química e substâncias naturais no México entre 1870 e 1960". Nesse sentido, a autora acompanha os primeiros farmacêuticos, naturalistas e médicos que se interessaram pela utilização médica das plantas endêmicas, em meados do século XIX, e pela criação de instituições de pesquisa, nas quais emergiram ensinos específicos para o surgimento da área disciplinar, a química das substâncias naturais, no México dos anos 1950.

Nadja Paraense dos Santos, João Massena Filho, Carla Cerqueira e Mônica Elias apresentam, no mesmo caminho da história das substâncias, o capítulo "Os pesquisadores do Instituto de Química Agrícola como disseminadores da pesquisa em produtos naturais no Brasil". Os autores apresentam historiadores das ciências que se dedicaram à formação e à consolidação dos grupos de pesquisa em química e produtos naturais no Brasil, nas últimas décadas do século $X X$, antes do debate contemporâneo acerca da biodiversidade. Essas pesquisas remontam à criação do Instituto de Química do Rio de Janeiro, em 1918, e sua expansão até a transformação em Instituto de Química Agrícola (IQA), em 1934. Um dos aspectos abordados neste texto é a articulação das pesquisas em química de plantas com outros centros científicos brasileiros e suas formas interdisciplinares. O ensaio mostra que a desestruturação do IQA não significou o fim da tradição científica, pois "seus cientistas deram continuidade a diferentes trabalhos em diferentes regiões do país. Assim, esse artigo também mostra parte da memória da história da ciência no Brasil".

O capítulo de Maria das Graças Bichara Zogbi, "A emergência da química e sua contribuição ao conhecimento científico dos recursos vegetais amazônicos", amplia a discussão da história da química na Amazônia. De acordo com a pesquisadora, a fundação do Instituto Nacional de Pesquisas da Amazônia (INPA), em 1952, inaugurou um laboratório de química no setor de tecnologia. No que se refere à região, a evolução da história das substâncias químicas e das plantas aromáticas foi essencial às pesquisas do INPA e do Museu Paraense Emílio Goeldi (MPEG), a partir da década de 1980. O texto apresenta um balanço histórico nesse campo científico.

O geógrafo Reinaldo Corrêa Costa e a química Cecília Verônica Nunez, ambos pesquisadores do INPA, no capítulo "Biodiversidade: usos sociais e bioprospecção", discutem um tema atual presente nos discursos e debates da agenda global relacionados à Amazônia e ao meio ambiente. Assim, conceituam e discutem o etnoconhecimento, a democratização do conhecimento e a lógica mercantil. Os autores criticam fortemente a Medida Provisória 2.186/2001, uma vez que se baseia na concepção individual dos direitos, sendo, dessa forma, totalmente desvinculada da possibilidade de uma propriedade intelectual coletiva e difusa.

Ao final do livro, o leitor encontrará o texto "Notas sobre produtos naturais da Amazônia", da antropóloga Diana Antonaz, que faleceu durante a finalização do livro. Doente, ficou impossibilitada de escrever o capítulo, mas os organizadores, em sua homenagem, incluíram o esboço na publicação. É uma pesquisa relevante, na medida em que a autora, além de apresentar as substâncias químicas, também descreve as instituições de pesquisa relacionadas ao tratamento e ao manejo dos produtos naturais na Amazônia.

Ao final da leitura, fica claro que os conhecimentos em torno dos produtos naturais costumam ser passados oralmente de geração para geração, método que salvaguarda as experiências dos antepassados, as quais foram e continuam sendo fundamentais para a sobrevivência das populações locais.

Essa obra é uma excelente referência para compreender a discussão atual sobre biodiversidade, em especial quando se constata que muitas das matérias-primas utilizadas pela indústria química mundial provêm de países ricos em biodiversidade, os quais, de forma contraditória, caracterizam-se por dificuldades econômicas e sociais enfrentadas pelas populações locais, como é o caso da Amazônia. 
